\title{
A SYSTEM DYNAMICS APPROACH FOR POULTRY OPERATION TO ACHIEVE ADDITIONAL BENEFITS
}

\author{
Mohammad Shamsuddoha \\ Mohammed Quaddus \\ Desmond Klass \\ Graduate School of Business \\ Curtin University, 78 Murray Street \\ Perth WA 6000, AUSTRALIA
}

\begin{abstract}
Poultry generates various wastes such as litter, reject and broken eggs, intestines, waste feeds, feather and culled birds. Most of the farm owners do not utlize these wastes for further by-product generation. Without profitability, farmers do not reuse their waste. System dynamics along with simulation is a tool that can be used to forecast the feasibility of waste and by-products generation. In this paper, we present a poultry model grounded on system dynamics to determine the interaction among factors in the system using a software package, Vensim. A case poultry industy in the city of Chittagong, Bangladesh was selected to conduct the study. The objectives of this paper are twofold. First, it develops a qualitative model on poultry operation. Second, it constructs a simulation model to explore possible opportunities available by recycling poultry wastes within the same poultry operation.
\end{abstract}

\section{INTRODUCTION}

Bangladesh is considered one of the suitable countries in the world for poultry rearing (Shamsuddoha and Sohel 2008). It is because of cheap labor, easy access to the community, available indigenous items and increasing demands. Its appropriateness can be justified due to employment creation, entrepreneur development and social and economic changes in rural, urban and sub-urban areas (Shamsuddoha, Quaddus, and Klass 2013). Applications of system dynamic concepts and simulation can easily guide farmers towards scientific farming with better profitability and sustainability (Shamsuddoha, Quaddus, and Klass 2013; Shamsuddoha, Quaddus, and Klass 2013). It is important to develop a mental model along with the stakeholders linkages in system dynamics (SD) modeling (Forrester 1961; Forrester 1994). System dynamics is a vibrant methodology based on developing simulation models to improve decision making, forecasting or problem solving performance (Vennix, Akkermans, and Rouwette 1996; Vennix and Vennix 1996; Vennix 1996; Andersen, Richardson, and Vennix 1997; Golnam et al. 2011). Such models can serve to develop policies that improve problem situations or provide potential solutions aimed at improving the situation (Vennix, Akkermans, and Rouwette 1996; Vennix and Vennix 1996; Vennix 1996; Andersen, Richardson, and Vennix 1997). Constructing a system dynamic model based on realistic information can model the reality more systematically (Lane and Oliva 1998). Manufacturing operation is quite complicated as it deals with environment, social and economic matters during different stages of production (Corbett and Kleindorfer 2003; Seuring and Muller 2008). Constructing a system dynamic model based on realistic information can model the reality more systematically (Lane and Oliva 1998). Manufacturing operation is quite complicated as it deals with environment, social and economic matters during different stages of production (Corbett and Kleindorfer 2003; Seuring and Muller 2008). 
It is difficult and challenging to preserve undamaged environment, have zero impact on society and provide consistent economic gains within manufacturing process that extend over long periods of time. In this situation, effective supply chain (SC) can result in efficient production (McAuley 1972), smooth supply (Fisher 1997), waste reuse, return and recycle (Saysel and Barlas 2001; Prahinski and Kocabasoglu 2006; Kocabasoglu, Prahinski, and Klassen 2007), and increase social benefits (Shamsuddoha 2011). The focus of this study confined on building poultry process model, later fit the model into the simulation environment in the computer. Then the simulation model replicates almost the real poultry process so that output of main products and wastes can be measured. Quantity of various wastes can help to take a decision whether recycling and reprocessing of poultry wastes will be profitable or not. This model also extended version from the real practices of the case industry in aspect of reversing wastes to the processing unit. Practically, some portion of the wastes reuse at the farm level and rest of the share used to supply towards third party as raw materials or dumped as final wastes. Such practices can be opened new opportunity for the existing and small business entrepreneurs.

\section{LITERATURE}

\subsection{Bangladesh Poultry}

Over $73 \%$ people lives in the rural areas and are highly dependent on agriculture and livestock system in Bangladesh. The contribution of the livestock sub-sector to GDP and the agriculture sector as a whole is currently $3.2 \%$ and $10.11 \%$ respectively (Discovery 2009). The Poultry industry is one of the major industries in the livestock sub-sector. Approximately $20 \%$ of the protein consumed in Bangladesh originates from poultry. Among poultry species, the chicken population is dominant over others, at almost $90 \%$, followed by ducks (8\%) and a small number of quail, pigeons and geese (Discovery 2009). To implement reverse supply chain (RSC) concepts in Bangladesh and within the poultry industry, there seems to be a low chances of product retrieval, return or reconditioning in the reality sense, as most chicken products are perishable. However, there are immense opportunities to reuse or recycle poultry wastage. By reusing poultry wastage, industries can make valuable products like fertilizers, bio-gas, pillows, charcoal, and bakery items. This kind of wastage conversion will help to maintain our environment and will add value at the customer end of the product cycle (Shamsuddoha 2011). Sustainability, Environment and RSC in the poultry industry have not yet received proper consideration by researchers. There are huge opportunities to conduct researches to develop the existing poultry operation in light of achieving organized supply chain, sustainability, profitability and optimality.

\subsection{Poultry Wastes}

There is huge quantity of various poultry wastes generated from the poultry operation. Unfortunately these wastes are dumped into vacant land and rivers and it caused severe environmental damage (Shamsuddoha 2011a, Shamsuddoha 2011b). Neglected wastes create environmental problems. Environmental problems spread various diseases, contaminate river or canal water, and spread odor to name a few. There are four different kind of poultry wastes, namely, litter (Burak Aksoy 2008), manure/compost (combination of poultry litter) (Rivera-Cruz et al. 2008), feathers (Shih 1993), broken eggs and intestines (Burns and Stickney 1980). Poultry litter can be the source of fertilizer (Gupta and Charles 1999), bio gas (Bala 1991), artificial charcoal and fish feed (Burns and Stickney 1980); feathers can be raw materials for the Bed industry (Shamsuddoha 2011b), broken eggs for the bakery and intestines for the fish farms (Shamsuddoha 2011b). 
Shamsuddoha, Quaddus, and Klass

\subsection{System Dynamics Model and its Application in the Poultry Operation}

System dynamics was familiarized by Jay Forrester in the 1960s as a modeling and simulation methodology for long-term decision-making and supply management and waste management (Chaerul, Tanaka, and Shekdar 2008). Such models are easy to control, link variables, and trace the changes through causal feedback loop system (Sterman 2000; Dyson and Chang 2005; Sterman 2006). The chicken industry supply chain (Minegishi and Thiel 2000), and its impact over environmental issues on product supply chain and product recovery (Georgiadis and Vlachos 2004), and waste management (Sudhir, Srinivasan, and Muraleedharan 1997; Karavezyris, Timpe, and Marzi 2002; Ulli-Beer 2003; Dyson and Chang 2005) have been studied using system dynamics and simulation modeling. A system dynamics model has also been proposed by Ulli-Beer (2003) to analyze the divergent local policy initiatives in solid waste recycling. The literature review showed no evidence of research on this current issue of poultry process in developing country like Bangladesh. Research gaps remain in the theory and practice of the poultry industry. No evidence was found of supply chain issues being considered in the light of the poultry industry in Bangladesh. This research gap motivated this study to enrich the literature and improve modern practices.

\section{METHODOLOGY}

Sometime after Forrester (1961) introduced system dynamics, Sterman (2000) conducted a number of studies to popularize it in the industrial world. Today, people are using system dynamics concepts to analyze their individual problems all over the world. For example the paper recycling industry (Spengler and Schröter 2003), poultry industry (Shamsuddoha, Quaddus, and Klass 2011b), business process reengineering (Sterman 1989) and Meadows's 'hog cycle'" (Meadows 1970) were developed on the basis of supply chains. The supply chain of an industry is the key to analyze situations through system dynamic modeling. Total supply chain consists of forward and reverse supply chain of a business process. Forward supply chain received priority over the reverse chains in academia (Aghalaya, Elias and Pati 2012). Systems dynamic deals with the dynamic behavior of a supply chains operation. Dynamic behavior depends on associated loop of a particular variable. A real life experience provides us with ideas that help us to conceptualizes and construct mental model. Table 1 shows how to construct model from a case industry through mental modeling and behavior. Richardson and Pugh (1981) developed a seven steps SD modeling process that begins with identification of the problem and system conceptualization of key variables and the relationships between them (Tarski 1983).

The methodological approach of this study is based on the systems dynamic methodology (Maani and Cavana 2007) with two phases of qualitative and quantitative approaches (Sterman 2000) shown in Table 1. In the first phase, system conceptualization was followed by constructing a mental model through business process observation over time. For structuring the problem systemically, a behaviorover-time information and chart was developed. In the second phase, a causal loop model was developed using a rigorous simulation package called Vensim DSS with version 6.01b. Both primary and secondary information was used in this study. Primary information was collected in September 2012 mainly through in-depth interviews with sample respondents from the poultry case industry. This research used in-depth interviews and observations to gain insights and develop a case poultry supply chain model. The total respondents included the top ten executives and case farm owners. Secondary information was collected from various books, referral journals, conference papers, statistical yearbooks and company record and reports. This study adopted a positivist ontology, empirical epistemology and quantitative methodology based on real supply chain cases of poultry processes. For this study, the design science methodology was chosen to extend the model (way of reuse or recycle wastes) to achieve goals (Simon 1969). The simulation package was used as a tool to analyze the poultry supply chain process in order to investigate the research objectives. 
Shamsuddoha, Quaddus, and Klass

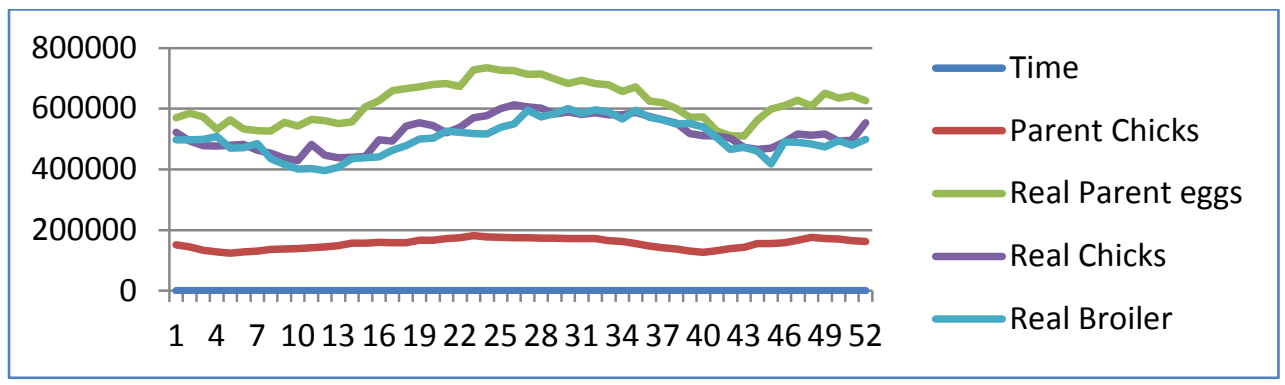

Figure 1: Historical graph of realistic data for key variable over time.

\subsection{Problem Structuring}

Historical behavior-over-time graphs (BOT) were developed based on key variables used to structure the problem. Variable performance over time was used to conceptualize the business trend and provide give appropriate input parameters to the system (Aghalaya, Elias, and Pati 2012). Historic information can provide parameters to represents present and future trends that show the behavior of growth, decline, and oscillations (Aghalaya, Elias, and Pati 2012). In this study, reference graph were drawn (Figure 1) to capture the historical output (behavior) of key variables of parent chicks, real parent eggs and real chicks. The data input in the graph contained 52 weeks (one year) and observed that all the key variables fluctuates number of time over mentioned time.

\section{CAUSAL MODEL BUILDING}

Causal loop diagramming (Sterman 2000; Sterman 2006) is an important part of a system dynamic model. Positive and negative feedback loops indicate the dynamic relationship among or between the key variables (Richardson 1986).

A causal loop diagram also visualizes how interrelated variables affect one another. The diagram consists of a set of nodes representing the variables connected together (Maani and Cavana 2007, Aghalaya, Elias, and Pati 2012). The relationships between variables, represented by arrows, can be labeled as positive or negative. Positive $(+)$ sign means increase (or decrease) in a variable causes a corresponding increase (or decrease) in a corresponding variable. If an increase in the causal variable caused a decrease in the affected variable, a negative (-) sign is placed near the head of the arrow (Aghalaya, Elias, and Pati 2012). According to Figure 2, there are numbers of loops displayed in this mental/qualitative/causal model. For examples:

Positive Feedback loop between 'Mature Parent and Parent Eggs': If mature parent supply increases then parent eggs will increase. Nevertheless, when parent eggs production escalates, mature parent will also increase to maintain consistent supply.

Negative feedback loop between 'Parent Chicks and 'Mature Parent': If parent chicks supply increases then mature parent will increase. However, when mature parent increases, parent chicks will be reduced due to parent chicks maturing as parents. 


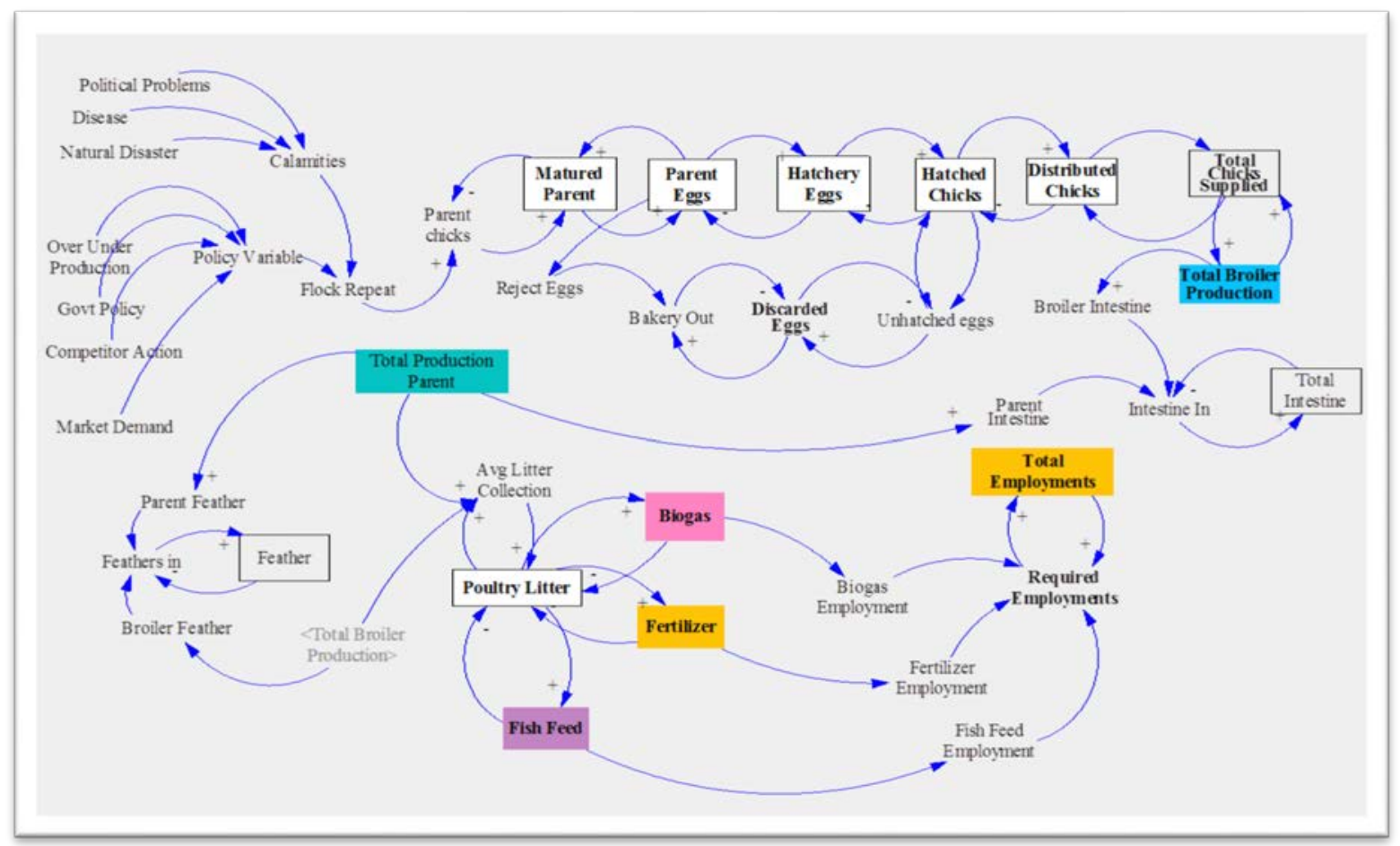

Figure 2: Causal diagram of poultry reverse supply chain.

\section{QUANTITATIVE (STOCK AND FLOW) SIMULATION MODEL}

Qualitative modeling helps to construct a quantitative model, which consists of stocks, flows and diagrams. Figure 3 was developed using the qualitative model displaying in figure 2 which also known as causal model. All the square boxes represented here as level or stock variable. These level variables are associated with the constant and auxiliary variables. The values of different variables were given input values based on the practical experience of respondents.

The model begins with "Broiler Chicks Lookup" variable of real data from the case industry using the last 52 weeks. This is the only input taken from reality and all outputs generated from simulation run by the Vensim package. This stock and flow diagram developed from the causal qualitative model of Figure 3 by determining appropriate rate, constant, auxiliary and level/stock variable. Stock variables are often changed using the determined value of associated constant and auxiliary variable. Most of the values were determined from primary sources of the case industry. This information was converted as mathematical values and equation for all connecting loops and variables. Some of the data was taken from standard practices from the case industry. When model development done, simulation run was conducted to see how it behaves. To get aggregate view of the whole model, synthesim run is an effective way to view it in the Vensim. Synthesim mode shows the graphical representation of levels and auxiliary variables. Constant variables are shown as side bar so that policy makers or modeler can experiment on it by increase or decrease the values instantly. 


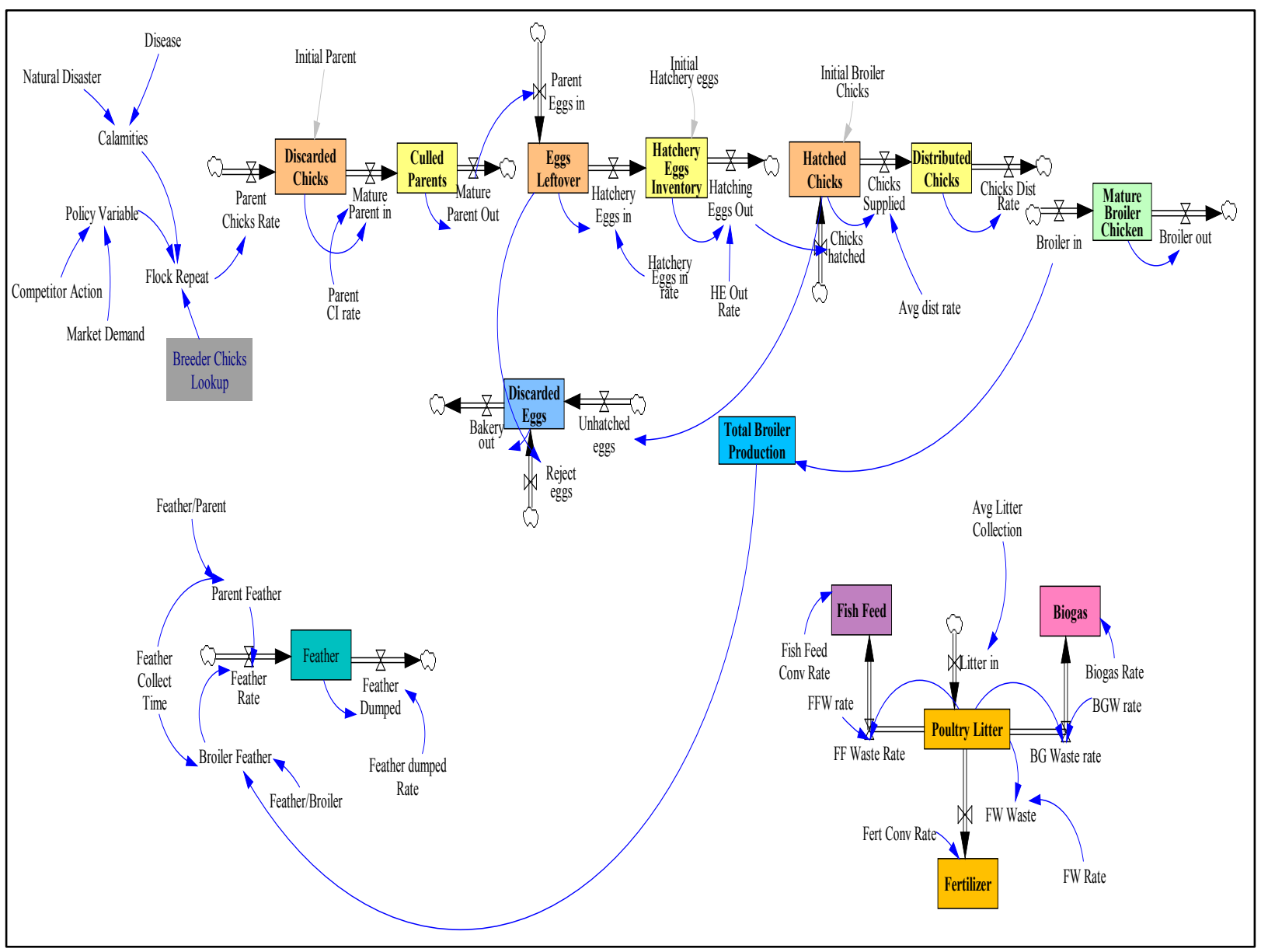

Figure 3: Poultry simulation model.

\section{RELIABILITY OF THE MODEL}

It is an integral part of a research study to check for validity and reliability. Validity and reliability tests are the prerequisites to builds confidence in system dynamics models (Forrester and Senge 1980; Barlas 1996). Reliability test can be done through comparing the simulated data with the real data. If it does not show any unusual behavior then it seems that model is reliable.

The blue and red lines are marked as simulated result and real life data respectively. Figure 5 clearly demonstrated key variables along with comparison of simulated and real data. For example, fish feed, biogas, fertilizers variables in figure 4 behaved perfectly except few sudden ups and down. Still this increase/ups (or decrease/down) are in acceptance range of 10 percent variation. It is observed that red and blue lines are very close with each other with minimum fluctuation. The simulation was been run for 156 weeks ( 3 years) whether real data available for 52 weeks only. This prediction will help the entrepreneurs to gain knowledge on future scenario. Therefore, the model is reliable as it behaves consistently with the time and real data. 
Shamsuddoha, Quaddus, and Klass

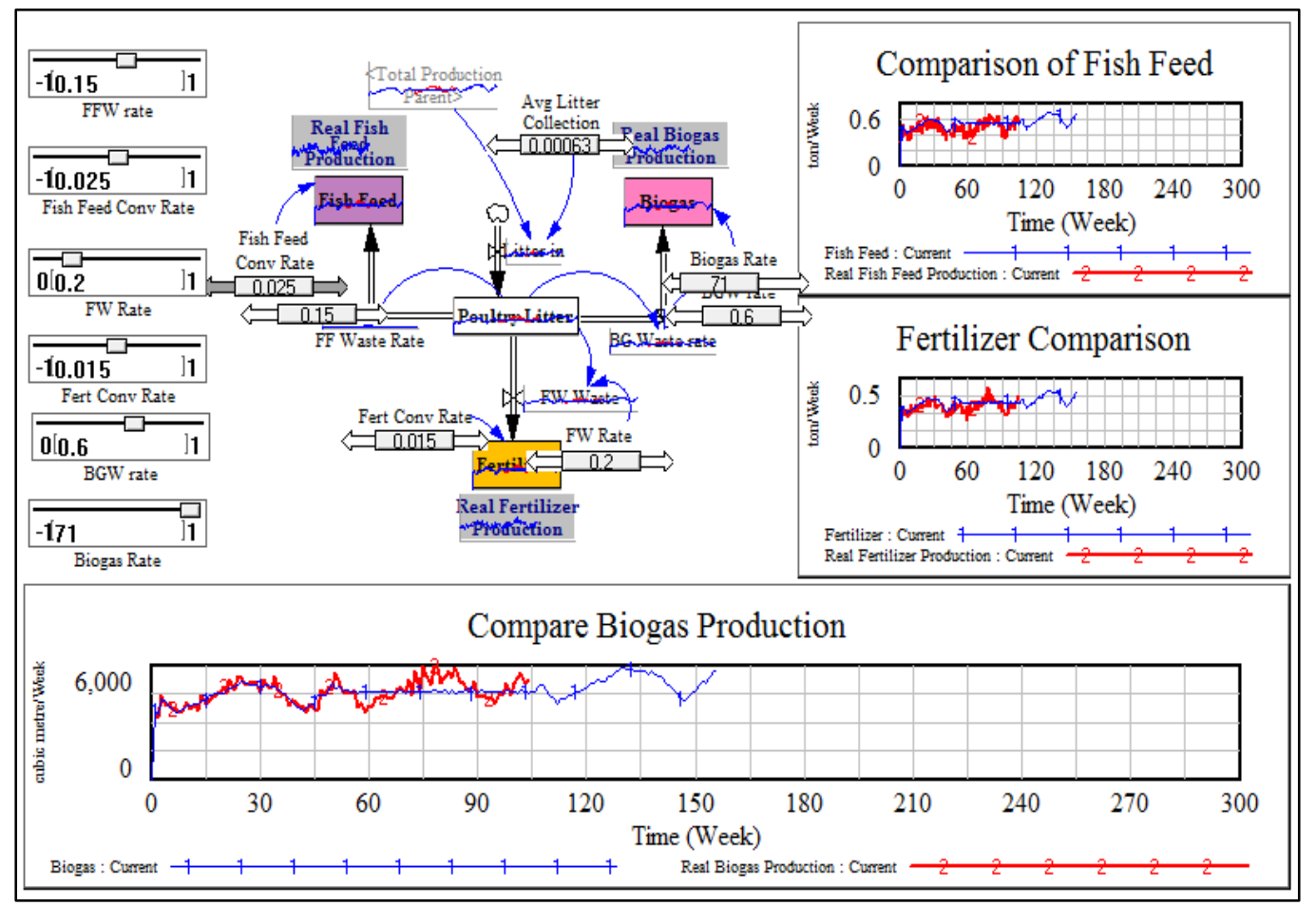

Figure 4: Few tests for reliability test.

\section{EXTREME CONDITION TEST (VALIDITY)}

Validity of model equations under extreme conditions resulting values beyond the projection/anticipation of what would happen under a similar condition in real life (Forrester and Senge 1980). This model was tested in various way of changing policy and constant variable, but it behaves as par expectation and trends. Finally, the model was tested based on policy implication by the policy makers. For example (in figure 5), policy maker want to reduce the poultry parent chicks 140,000 to 1,00000 , increase weekly minimum egg production of 3.9 eggs/week to 4 eggs/week, increase maximum eggs production 3.97 eggs/week to 4.294 eggs/weeks and the likes. Therefore, the model fulfills the criterion to be valid.
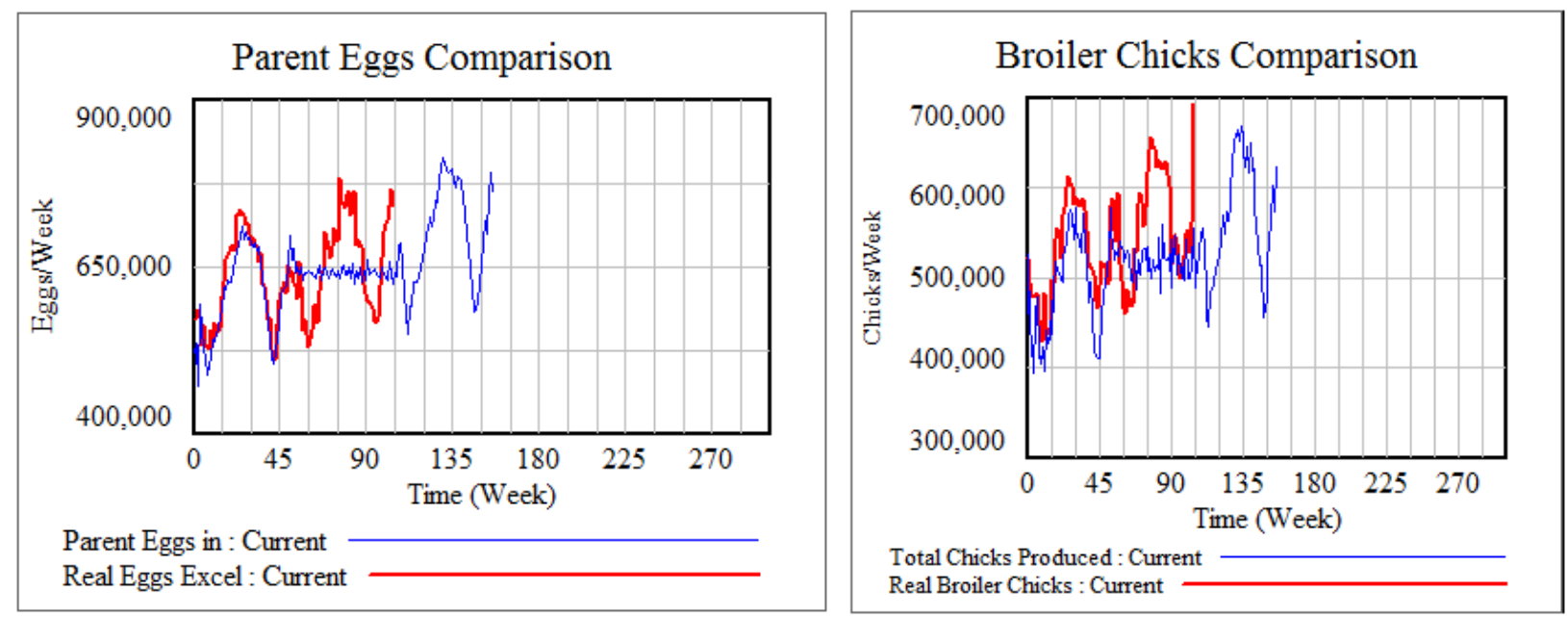

Figure 5: Extreme condition test of key variables. 
Shamsuddoha, Quaddus, and Klass

\section{MODEL RESULT AND DISCUSSION}

Poultry leading countries on poultry farming have adopted many latest technology and concepts in their operation. Consequently, they have gained significant success in poultry rearing and processing, demand, supply mitigating, and wastes management. These innovations have yet to be adopted in developing countries like Bangladesh because of factors that include financial strength, technological inability, inconsistent power supply, land scarcity, failed to predict futuristic scenario, improper disease management, unsure about the market demand, natural disaster and government irresponsiveness. This study has developed such a model, which is one of the major contributions in light of poultry process in Bangladesh. Such model can be experimented by the poultry owners and policymakers' in various ways before implementing a dynamic decision. Dynamic decisions can be based on poultry flock size, waste procurement, employment requirements, demand and supply situation, price, profit and the likes. In figure 3, dynamic relationship between main variables was diagramed in a causal model. At the same time stock and flow model sketched based on causal model, which is almost similar to practical poultry process. This virtual process can able to see 'what if' situations within the process. For example, what quantity of poultry wastes can be generated if particular input was given to the system? Obviously, this model can save the time and practical experiments for the farmers, which save time and money. The model also explored numbers of opportunities within the poultry operation specially in reversing poultry wastes. The model also depicted various by-products (mainly, biogas, fish product and fertilizers) procurement from existing poultry wastes. This study also reveals the opportunity of using unused wastes like poultry feathers and intestines as many countries are making valuable products from them. For example, poultry soft feathers are using for making mattress, pillow and other bedding materials. All the results were reliable based on reliability test and checked the validity using extreme condition test in figure 5. All the figures demonstrated desired results, which is a good sign for the poultry stakeholders. The researchers also believe that this model can be used at any environment to measure poultry wastes and generate by-products from them. Moreover, it will help the farmers and policymakers to integrate forward and reverse supply chain to be more productive poultry industry.

\section{CONCLUSIONS}

In brief, the idea of system dynamics simulation modeling are using in so many sectors all over the world. The great benefit of this methodology is its capability of providing futuristic behavior that helps the decision makers to prepare themselves to act on time. It is now presents a great opportunity considerable idea for the poultry entrepreneurs to utilize their potentiality to gain maximum benefits. Proper poultry management can help to achieve economic, social and environmental benefits. It can also create more employment opportunities, increase the scope of introducing small and medium scale of industry, help to achieve social benefits and help to keep our environment clean and hygiene. There are also many benefits associated with sustainable poultry farming. The output from the model, in addition to being able to measure quantity but also associated consequences, which help the poultry stakeholders to make the right decision in a particular situation. Future research can extend to meticulous particulars of the total industry operation and its optimality.

\section{REFERENCES}

Aghalaya, S. N., A. A. Elias, and R. K. Pati. 2012. "Analysing Reverse Logistics in the Indian Pharmaceuticals Industry: A Systems Approach". In 26th Australian and New Zealand Academy of Management (ANZAM) Conference 2012 Perth. 
Andersen, D. F., G. P. Richardson, and Jac AM Vennix. 1997. "Group Model Building: Adding More Science to the Craft." System Dynamics Review 13 (2):187-201.

Bala, B. K. 1991. "System Dynamics Modelling and Simulation of Biogas Production Systems." Renewable Energy 1 (5-6):723.

Barlas, Y. 1996. "Formal Aspects Of Model Validity And Validation In System Dynamics." System Dynamics Review 12 (3):183-210.

Burak A., H. T. Cullinan, N. E. Sammons Jr, and M. R. Edenb. 2008. "Identification of Optimal Poultry Litter Biorefinery Location in Alabama Through Minimization of Feedstock Transportation Cost." Environmental Progress 27 (4).

Burns, P. R., and R. R. Stickney. 1980. "Growth of Tilapia Aurea in Ponds Receiving Poultry Wastes." Aquaculture 20 (2):117-121.

Chaerul, M., M. Tanaka, and A. V. Shekdar. 2008. "A System Dynamics Approach for Hospital Waste Management." Waste Management 28 (2):442-449.

Corbett, C. J., and P. R. Kleindorfer. 2003. "Environmental Management and Operations Management: Introduction to the Third Special Issue." Production and Operations Management 12 (3):287-289.

Discovery_Bangladesh. 2013. Bangladesh Fisheries and Livestock. Business Information Bangladesh 2009 [cited $\quad$ March 22 2013]. Available from http://www.discoverybangladesh.com/meetbangladesh/fisheries_livestock.html.

Dyson, B., and N. Chang. 2005. "Forecasting Municipal Solid Waste Generation in a Fast-Growing Urban Region With System Dynamics Modeling." Waste Management 25 (7):669-679.

Fisher, M. 1997. What is the Right Supply Chain for Your Product? Vol. March-April. USA: Harvard Business Review.

Forrester, J. W. 1961. Industrial Dynamics. Cambridge (MA): The MIT Press.

Forrester, J. W. 1994. "System Dynamics, Systems Thinking, and Soft OR.” System Dynamics Review 10 (2).

Forrester, J. W., and P. M. Senge. 1980. "Tests for Building Confidence in System Dynamics Models." TIMS Studies in Management Sciences 14:209-228.

Georgiadis, P., and D. Vlachos. 2004. "The effect of environmental awareness on product recovery networks design." European Journal of Operational Research 157:449-464.

Golnam, A., G. Tapandjieva, S. Viana, and A. Wegmann. 2011. "Problem Structuring Methods in System Dynamics Modeling: a Cognitive Fit Perspective." [Accessed March 22 2013]. Available from http://infoscience.epfl.ch/record/169643/files/Problem\%20Structuring\%20Methods\%20in\%20System $\% 20$ Dynamics\%20Modeling-Camera\%20Ready.pdf

Gupta, G., and S. Charles. 1999. "Trace Elements in Soils Fertilized with Poultry Litter." Poultry Science 78:1695-1698.

Karavezyris, V., K. P. Timpe, and R. Marzi. 2002. "Application of System Dynamics and Fuzzy Logic to Forecasting of Municipal Solid Waste." Mathematics and Computers in simulation 60 (3):149-158.

Kocabasoglu, C., C. Prahinski, and R. D. Klassen. 2007. "Linking Forward and Reverse Supply Chain Investments: The Role of Business Uncertainty." Journal of Operations Management 25:1141-1160.

Lane, D. C., and R. Oliva. 1998. "The greater whole: Towards a Synthesis of System Dynamics and Soft Systems Methodology.” European Journal of Operational Research 107 (1):214-235.

Maani, K. E., and R. Y. Cavana. 2007. Systems Thinking, System Dynamics: Managing Change and Complexity. Vol. 2nd. Auckland: Pearson Education (NZ) and Prentice Hall.

McAuley, J. 1972. "Machine Grouping for Efficient Production.” Production Engineer 51 (2):53-57.

Meadows, D. L. 1970. Dynamics of Commodity Production Cycles. Cambridge (MA): Wright-Allen Press.

Minegishi, S., and D. Thiel. 2000. "System Dynamics Modeling and Simulation of a Particular Food Supply Chain." Simulation Practice and Theory 8 (5):321-339. 
Prahinski, C., and C. Kocabasoglu. 2006. "Empirical Research Opportunities in Reverse Supply Chains." Omega: The International Journal of Management Science 34 (6):519-532.

Richardson, G. P., and D. F. Andersen. 2006. "Teamwork in Group Model Building." System Dynamics Review 11 (2):113-137.

Richardson, G. P., and A. I. Pugh III. 1981. Introduction to System Dynamics Modeling with DYNAMO: Productivity Press Inc.

Richardson, G. P. 1986. "Problems with Causal-Loop Diagrams.” System Dynamics Review 2 (2):158170.

Rivera-Cruz, M. C., A. T. Narc1'a, G. C. Ballona, J. Kohler, F. Caravaca, and A. Rolda'n. 2008. "Poultry Manure and Banana Waste are Effective Biofertilizer Carriers for Promoting Plant Growth and Soil Sustainability In Banana Crops.” Soil Biology \& Biochemistry 40:3092-3095.

Saysel, A. K., and Y. Barlas. 2001. "A Dynamic Model of Salinization on Irrigated Lands." Ecological Modelling 139 (2):177-199.

Seuring, S., and M. Muller. 2008. "From a Literature Review to a Conceptual Framework for Sustainable Supply Chain Management." Journal of Cleaner Production 16 (15):1699-1710.

Shamsuddoha, M. 2011a. Applying Reverse Supply Chain in the Poultry Industry. In Emerging Research Initiatives and Developments in Business: CGSB Research Forum 2011, edited by Therese Jefferson, Mohammad Shamsuddoha and Ellen Young. Perth, Australia: Curtin University.

Shamsuddoha, M. 2011b. Reverse Supply Chain Process as Environmental Sustainability in the Poultry Industry of Bangladesh. In Doctoral Colloquium 2011, edited by Jenny Goodison. Perth: Curtin Business School, Curtin University.

Shamsuddoha, M., D. Klass, and M. Quaddus. 2011. Economic, Social and Environmental Benefits Through Poultry Forward and Reverse Supply Chain. Perth: Curtin University.

Shamsuddoha, M., D. Klass, and M. Quaddus. 2013a. Poultry Supply Chain: A System Approach. In 31st International Conference of the System Dynamics Society. Cambridge, Massachusetts USA: System Dynamics Society.

Shamsuddoha, M., D. Klass, and M. Quaddus. 2013b. Poultry Wastage Re-usage Through Reverse Supply Chain Process to Attain Environmental Sustainability. Curtin University.

Shamsuddoha, M., and M. H. Sohel. 2008. "Poultry Rearing - An Alternative Income Generating Activity for Rural Women Development of Bangladesh." The Chittagong University Journal of Business Administration, Bangladesh 20 (1):119-132.

Shih, J. C. H. 1993. "Recent Development in Poultry Waste Digestion and Feather Utilization: A Review." Poultry Science 72 (9):1617-1620.

Simon, H. 1969. The sciences of the artificial. Cambridge: MIT Press.

Spengler, T., and M. Schröter. 2003. "Strategic Management of Spare Parts in Closed-Loop Supply Chains - A System Dynamics Approach.” Interfaces 33 (6):7-17.

Sterman, J. D. 2000. Business Dynamics: Systems Thinking and Modeling for a Complex World. Boston: Irwin McGraw-Hill.

Sterman, J. D. 1989. "Modeling Managerial Behavior: Misperceptions of Feedback in A Dynamic Decision Making Experiment." Management Science 35 (3):321-339.

Sterman, J. D. 2006. Operational and Behavioural Causes of Supply Chain Instability. Edited by O. Carranza and F. Villegas, The Bullwhip Effect in Supply Chain. New York, NY: Palgrave Macmillan.

Sudhir, V. G. Srinivasan, and V. R. Muraleedharan. 1997. "Planning for Sustainable Solid Waste Management in Urban India." System Dynamics Review 13 (3):223-246.

Tarski, A. 1983. Logic, Semantics, Metamathematics: Papers from 1923 To 1938: Hackett Publishing Company Incorporated.

Ulli-Beer, S. 2003. Dynamic Interactions Between Citizen Choice and Preferences and Public Policy Initiatives. A System Dynamics Model of Recycling Dynamics in a Typical Swiss Locality. Paper Read at International Conference of The System Dynamics Society. 
Vennix, J. A. M. 1996. Group Model Building: Facilitating Team Learning Using System Dynamics. Chichester Wiley.

Vennix, J. A. M., H. A. Akkermans, and E. A. J. A. Rouwette. 1996. "Group Model-Building to Facilitate Organizational Change: An Exploratory Study.” System Dynamics Review 12 (1):39-58.

Vennix, J. A. M., and J. Vennix. 1996. Group model building: Facilitating team learning using system dynamics: J. Wiley.

\section{AUTHOR BIOGRAPHIES}

MOHAMMAD SHAMSUDDOHA studied business at the University of Chittagong, Bangladesh for his MBA and M.Phil. And now he is doing PhD at Curtin University, Perth, Western Australia. He is serving as Associate Professor of Marketing at the University of Chittagong since 2002. He is also working as a research associate at Curtin University under Professor Jeremy Galbreath. He is basically from Marketing domain but his current research is very much concentric on Supply Chain Management along with System Dynamics and Simulation modelling. He has more than 50 papers published and presented in different Conference and Journal all over the world. His email address is mdsdoha@gmail.com.

MOHAMMED QUADDUS did his PhD studied Information Systems at the University of Pittsburgh in mid 70s. He is currently working as a Director of Curtin Graduate School of Business, Curtin University, Perth, Western Australia. He has numbers of Doctoral students and more than 40 students have been awarded under his direct supervision. He did his Bachelor in BUET, Bangladesh then followed by AIT Masters and Pittsburgh MBA in early 70s. He has more than 200 quality Journal and Conference paper published in all over the world. His email address is Mohammed.Quaddus@gsb.curtin.edu.au.

DESMOND KLASS is serving as an Associate Professor of Curtin Graduate School of Business, Curtin University, Perth, Western Australia. He has numbers of quality papers published in different Journal and Conference Proceedings. His email address is Des.Klass@gsb.curtin.edu.au. 